\title{
Clinical and pathologic factors predicting reclassification in active surveillance cohorts
}

\author{
Pablo S. Sierra ${ }^{1}$, Shivashankar Damodaran ${ }^{2}$, David Jarrard ${ }^{2,3}$ \\ ${ }^{1}$ Fundacion Valle del Lili -Universidad Icesi, Cali, Colombia; ${ }^{2}$ Department of Urology, University of \\ Wisconsin School of Medicine and Public Health, Madison, WI, USA; ${ }^{3}$ University of Wisconsin Carbone \\ Cancer Center, Madison, WI, USA
}

\section{ABSTRACT}

The incidence of small, lower risk well-differentiated prostate cancer is increasing and almost half of the patients with this diagnosis are candidates for initial conservative management in an attempt to avoid overtreatment and morbidity associated with surgery or radiation. A proportion of patients labeled as low risk, candidates for Active Surveillance (AS), harbor aggressive disease and would benefit from definitive treatment. The focus of this review is to identify clinicopathologic features that may help identify these less optimal AS candidates.

A systematic Medline/PubMed Review was performed in January 2017 according to PRISMA guidelines; 83 articles were selected for full text review according to their relevance and after applying limits described.

For patients meeting AS criteria including Gleason Score 6, several factors can assist in predicting those patients that are at higher risk for reclassification including higher PSA density, bilateral cancer, African American race, small prostate volume and low testosterone. Nomograms combining these features improve risk stratification.

Clinical and pathologic features provide a significant amount of information for risk stratification $(>70 \%$ ) for patients considering active surveillance. Higher risk patient subgroups can benefit from further evaluation or consideration of treatment. Recommendations will continue to evolve as data from longer term AS cohorts matures.

\section{ARTICLE INFO}

\section{Keywords:}

Prostatic Neoplasms;

Neoplasm Grading

Int Braz J Urol. 2018; 44: 440-51

Submitted for publication:

May 24, 2017

Accepted after revision:

November 12, 2017

Published as Ahead of Print: January 14, 2018

\section{INTRODUCTION}

Currently, 15-20\% of men are diagnosed with prostate cancer (PC) during their lifetime, but the mortality risk is only $3 \%$ (1). The incidence of small, low risk, well-differentiated PC is increasing, mainly as a result of PSA screening and increased intensity prostate biopsy schemes (2). Many of these patients would never develop symptomatic disease during their lifespan and therefore do not benefit from definitive treatment due to the indolent behavior of low risk PC $(3,4)$. It is estimated that $45 \%$ of PC patients diagnosed with
PSA screening are candidates for conservative treatment and about $2 / 3$ of these men will ultimately avoid definitive treatment $(4,5)$. The utilization of AS is increasing and in a recent analysis utilizing the CAPSURE database, the use of AS ranged from 6.7\% to $14.3 \%$ from 1990 through 2009 but increased sharply between 2010 to 2013 when $40.4 \%$ of low risk patients had opted for this approach (6).

AS is an accepted option, and one of first line treatments offered for the initial management of low risk PC patients. Low-risk PC has been defined by D'Amico as Gleason score of 6 or less, PSA less than $10 \mathrm{mg} / \mathrm{mL}$, and a tumor that is either 
non-palpable or only palpable in less than half of one lobe of the prostate (clinical stage T1c or T2a) (7). These patients have a low possibility of reclassification with only $16-18 \%$ of men requiring treatment at 2 years in several large AS cohorts (8-11). The main objective for treatment planning is trying to achieve the correct timing of curative treatment once previously established thresholds that indicate aggressive disease (disease progression) are reached, in order to preserve quality of life and avoid risk of complications associated with other definitive therapies, including surgery and radiation.

It is expected that up to $30-50 \%$ of patients with low risk disease would be upgraded to Gleason score (7 or greater) or upstaged at the time of radical prostatectomy (RP) (12-14). This is clinically important, because Gleason score upgrading including pattern 4 results in worse oncologic outcomes such as increased risk of biochemical recurrence, need for adjuvant therapy and increase of cancer-specific mortality (15). A recent longer-term analysis of an AS cohort demonstrated that patients with GS4 have a higher risk of metastasis (16). It is imperative to define patients at low risk of progression after diagnosis and differentiate them from patients with occult aggressive cancer behavior. It is also important to obtain patient progression data from actual AS cohorts, rather than from radical prostatectomy specimens, which will require waiting additional years for current larger cohorts to mature because of the long disease history.

\section{MATERIALS AND METHODS}

A systematic MEDLINE/PubMed review was performed in mid 2016 according to the PRISMA guidelines. The main search terms were "active surveillance", "prostate cancer" and "upgrading" as a secondary keyword, 2168 articles were retrieved, 1599 articles remained after applying limits for papers published after 2008. The search result was first screened for relevance by title and limited to English and Spanish literature, abstracts were read and 83 publications of interest were selected for full text review. The search was complemented with own files articles, hand search and articles suggested by important publications until no additional papers were retrieved. The search sensitivity was evaluated by comparing the articles identified against those already known by the authors and those cited in previous seminal reviews. If an article was missed, the title and abstract where carefully reviewed to identify terms that would improve the sensitivity.

\section{OPTIMAL CANDIDATES FOR ACTIVE SURVEILLANCE}

The selection of men for AS has been traditionally guided by clinicopathological features that indicate the patient presents with an organ confined, well-differentiated tumor. Life expectancy and comorbidities are important determinants for a watchful waiting (WW) versus AS strategy. Patients with a limited life expectancy are better candidates for WW which consists of less frequent PSA monitoring, no further prostate biopsies, and the application of androgen deprivation therapy if the disease becomes metastatic. For patients on AS, this switch to WW does not occur infrequently. Stratified by age, 10\% of 55-yearold men switched to WW, but 50\% of 70-year-old men moved to watchful waiting in one study (17). In WW, a strategy of non-invasive monitoring with PSA and DRE every 6 months leads to very low prostate cancer-specific mortality at 10 years, making this an effective strategy in carefully selected patients (18).

Current available information is limited to non-randomized clinical trials with follow-up of less than 10 years (the majority $<5$ years) and the recommendation from major clinical guidelines is that AS should be offered only in selected lower risk patients. However, there is no consensus on the optimal method of selecting men for AS, and depending on the clinical guidelines or on studies from different cohorts, selection criteria can change. The National Comprehensive Cancer Network (NCCN) guidelines define very low risk PC as those with T1c disease, Gleason score $\leq 6$, PSA $<10 \mathrm{ng} / \mathrm{mL}$, fewer than three positive biopsy cores, with $\leq 50$ percent cancer in each core, and a prostate-specific antigen density (PSAD) $<0.15 \mathrm{ng} / \mathrm{mL} / \mathrm{g}$. In this very low-risk group, the NCCN recommends active surveillance as the pre- 
ferred option for those with a life expectancy less than 20 years. Very low risk patients in the Epstein criteria employ one or two positive cores, no core with more than 50\% involvement and a PSA density of less than 0.15. Epstein low risk disease is defined as Gleason T1- T2a disease along with Gleason score $\leq 6$ and PSA < 10ng/ $\mathrm{mL}$. In this category, NCCN recommends AS, surgery or radiation if life expectancy $>10 y e-$ ars (19). The American Urological Association (AUA) (20), and The European Association of Urology (EAU) (21) recommendations are listed in Table-1 with other commonly used criteria.

One concern is limiting this population so severely that relatively few patients would be candidates. Cancer Care Ontario (CCO) guidelines, in addition, recommends GS 7 cancer $[3+4]$, who have low-volume and percentage Gleason 4 pattern pathology $(<10$ to 20 percent pattern 4), and/or age older than 75 years (22). (Table-1).

Overholser et al. compared outcomes between men with very low risk (Epstein criteria) and low-intermediate risk disease (4 or fewer cores with GS 6 cancer and/or only 1 core of Gleason $3+4$ cancer $<15 \%$ ) and found no differences in adverse pathological features such as upgrading or upstaging at radical prostatectomy (23). There was an obvious increase in patients eligible for AS from 44\% to 68\% of their population by expanding these selection criteria. The risks of adverse specific outcomes will likely be higher with the inclusion of men with more intermediate risk features, but the absolute risk of death may still be low (24). In the previously described study (23), only two of the 320 patients either experienced metastatic disease or died of PC during the 12-year study period. Notably, in the recent TGCA analysis, GS 6 tumors were all diploid, but increased grade greater than 4 was associated with increased polyploidy (25). The new International Society of Uropathology (ISUP) Gleason grade groups classifies Gleason $6,3+4,4+3,8$ and $9-10$ as grade groups of 1,2 , 3,4 and 5 respectively (26). The adaptation of this grade system by urologists will witness incorporation of this system in active surveillance protocols.

Expanding criteria for AS without compromising absolute outcomes will be provided in the future with additional follow up in surveillance cohorts.

Mortality and quality of life are indicators that have been infrequently applied to these patient populations and will be an area of development in the future. Bellardita et al. summarized the evidence on quality of life in AS cohorts in a systematic review in 2014 examining ten research based studies that measured this outcome (27). Patients undergoing AS reported good quality of life in diverse questionnaires and did not appear to suffer major psychological

Table 1 - Commonly utilized clinicopathologic criteria for active surveillance.

\begin{tabular}{lcccccc}
\hline AS criteria & PSA & Clinical stage & Gleason & Core & PSAD & Age/Life expectancy \\
\hline NCCN very low risk & 10 & T1c & 6 & $<3$ core $/<50 \%$ & $<0.15$ & $<20$ years \\
NCCN low risk & 10 & T1- T2a & 6 & & $>10$ years \\
CCO & & 6 & Low volume & \\
& & & $7(3+4)$ & $<10-20 \%$ of 4 pattern & \\
AUA & 10 & T1c - T2a & 6 & & $>15$ years \\
EAU & 10 & T1c - T2a & 6 & $<3$ core $/<50 \%$ & $<0.15$ & $>10$ years \\
\hline
\end{tabular}

NCCN = National Comprehensive Cancer Network; $\mathbf{C C O}=$ Cancer Care Ontario; $\mathbf{A U A}=$ American Urological Association; $\mathbf{E A U}=$ European Association of Urology; PSAD = PSA density 
impact, indeed overall scores were comparable or better than those of patients undergoing radical treatment.

Another factor associated with AS is the risk associated with monitoring itself, namely infection or other complications after prostate biopsy (28). A large population based study demonstrated that patients undergoing a transrectal biopsy had more than twice the risk of hospitalization within 30 days of the procedure compared to a control population (29). There is a recent chronological trend towards increased infection with antibiotic resistant organisms after transrectal biopsy $(30,31)$. Bleeding and pain from the procedure also impact patients undergoing prostate biopsy. Hematuria and hematospermia are common after the procedure, but typically mild and self-limiting (32).

Selection criteria and patient populations continue to evolve because AS cohorts still have relatively short follow-up compared to PC's natural evolution.

\section{CLINICAL AND PATHOLOGIC FACTORS THAT PRE- DICT RECLASSIFICATION}

There is a concern in clinical practice that some patients diagnosed initially as low-risk PC actually have aggressive disease. Many studies have demonstrated the frequent disparity between Gleason scores reported on prostate biopsy and at radical prostatectomy, that is in part explained because of misdiagnosis on first biopsy or also because most AS programs only use Gleason score, clinical stage and PSA to enroll patients. excluding other possible important predictors such as age, PSA density (PSAD), prostate volume, obesity, and race. These features are summarized in Table- 2 .

Radical prostatectomy specimens provide an opportunity to determine the actual grade and stage of low risk patients in modern cohorts and determine those features that best predict upgrading. Further pretreatment risk stratification in patients labeled as "low risk" is of paramount importance. There are externally validated clinical predictors (nomograms) that could help identifying this population (33). Delaying definitive treatment in this kind of patients could result in disease progression and adverse outcomes $(34,35)$.

\section{Tumor Volume}

In most malignancies, tumor volume is an important indicator for disease aggressiveness as well as in PC, but one unique aspect of PC is its multifocal origin (36). The physician usually has only an indirect estimation of tumor volume in the TRUS biopsy based on the number of cancerous cores, and the percentage of cancer involvement within each core. Unfortunately, at TRUS biopsy, the current standard for PC diagnosis, larger prostates may be under sampled or the tumor volume underrepresented.

Even with the above caveats that TRUS biopsy has, indirect representation of tumor volume by assessing maximal core involvement and number of cores with cancer has been found to be important predictors for GSU, AS failure and functions as a trigger that indicates the necessity of treatment of these patients. Bul et al. found increasing number of positive cores as one of the strongest predictors for reclassification (OR 2.2; 95\%CI 1.67-2.81; $p<0.001$ ) (8). Klotz et al. described number of cores involved with cancer as a factor that correlates with risk of reclassification in the largest AS cohort described to date (10). Results are corroborated by other investigations $(37,38)$.

Higher tumor volume has a direct proportional relationship with probability of reclassification on follow-up biopsies and subsequent AS failure. Furthermore, having bilateral tumor in the initial biopsy or developing a bilateral tumor on follow-up biopsies are associated with an increased risk of failing AS because of increasing cancer cores $>2$, increasing maximal core involvement $>50 \%$ and Gleason score upgrading (HR 3.8; 95\% CI 2.046-7.058; $\mathrm{p}<0.0001)$. This association was encountered in our AS cohort [unpublished data].

\section{PSA density}

Major AS cohorts and studies have repeatedly demonstrated PSA density (PSAD) can predict progression of the disease. The multi- 
Table 2 - Clinicopathologic predictors of upgrading gleason score $(>6)$ during active surveillance from published studies.

\begin{tabular}{|c|c|c|c|}
\hline Markers & Studies & Correlates & Strength \\
\hline No. positive cores & $\begin{array}{l}\text { Bul et al., Klotz et al., Truong et al., } \\
\text { Iremashvili et al. }\end{array}$ & Higher cancer volume & +++ \\
\hline $\begin{array}{l}\text { Max. \% core } \\
\text { involvement }\end{array}$ & Klotz et al., Truong et al. & Higher cancer volume & +++ \\
\hline PSA Density & $\begin{array}{l}\text { Bul et al., Kobt et al., San Francisco et al., } \\
\text { Truong et al., Iremashvili et al., REDEEM }\end{array}$ & $\begin{array}{l}\text { Higher cancer volume, Low } \\
\text { testosterone }\end{array}$ & +++ \\
\hline Small prostate volume & $\begin{array}{l}\text { Freedland et al., Davies et al., Gershman } \\
\text { et al. }\end{array}$ & Low testosterone & ++ \\
\hline Obesity & De Cobelli et al., Truong et al. & $\begin{array}{l}\text { Low testosterone, hyperestrogenism, } \\
\text { hyperinsulinemia, elevated adipokines }\end{array}$ & ++ \\
\hline $\begin{array}{l}\text { Inherited cancer } \\
\text { syndromes }\end{array}$ & Castro et al., Bratt et al. & Aggressive cancer, metastases risk & + \\
\hline Hypogonadism & Pichon et al., Gao et al. & Aggressive cancer & + \\
\hline $\begin{array}{l}\text { African American } \\
\text { ethnicity }\end{array}$ & Rebbeck et al., Sundi et al., Abern et al. & $\begin{array}{l}\text { Aggressive cancer, advanced stage } \\
\text { and poorer outcomes }\end{array}$ & + \\
\hline PSA velocity & Kates et al. & $\begin{array}{c}\text { Aggressive cancer/ }>4 \text { years on } \\
\text { surveillance }\end{array}$ & $+/-$ \\
\hline Family history & $\begin{array}{l}\text { Hemminki et al., Kupelian et al., Kundu et } \\
\text { al., Selkirk et al.. }\end{array}$ & Aggressive cancer & $+/-$ \\
\hline
\end{tabular}

+++ = Strong association; ++ = Moderate association; + = Weak association; +/- = Doubfful association

national European study PRIAS found PSAD to be one of the two strongest predictors for reclassification and switching to definitive treatment (8). Kobt et al. recognized in their AS cohort that $\mathrm{PSAD}<0.15$ may suggest indolent disease (39) and San Francisco et al. went further and reported that a PSAD greater than 0.08 can predict pathological progression (40). These results were confirmed recently in a larger AS cohort (41). PSA density seems to be a key factor in predicting PC progression, in the first sub analysis of the REDEEM study the authors could not prove dutasteride prevents progression in AS, but found PSAD to be a predictor for disease progression (42). It appears that PSAD should be included not only as a selection criterion but also as a trigger for intervention or as an indicator of AS failure (OR 3.0 (2.14 - 4.28, $\mathrm{p}<0.01$ ) (8). Smaller prostates are more prone to GSU at radical prostatectomy possibly because a small gland size may be a marker of lower androgenicity, and cancer growing in this environment may have a more aggressive biology as suggested previously (43). Several studies have suggested that lower volume prostates harbor a greater potential for cancer upgrading. Davies et al. and Gershman et al. found a smaller prostate size to be an independent predictor of upgrading OR 0.58 and OR 0.59 respectively, and these results have been corroborated in different publications $(44,45)$.

Most major urological societies recommend PSAD as a selection criterion in clinical guidelines and AS cohorts (being adopted now in the NCCN guidelines, PRIAS study (8), Johns Hopkins cohort (11) because previous studies not 
using PSAD as a cutpoint have demonstrated higher rates of upgrading in AS populations $(10,33)$.

\section{Obesity}

Increased body mass index as a component of the metabolic syndrome is a major risk factor for deleterious chronic diseases like diabetes, cardiovascular disease, hypertension and stroke. Obesity generates high levels of insulin and IGF-1, elevated estrogen, reduced testosterone and increased levels of adipokines that create an environment of chronic subclinical inflammation that would favor the development of more aggressive PC (46). Compared with normal or overweight men eligible for AS, obese patients are at higher risk of upgrading or upstaging. Furthermore, obesity (BMI>32) has been found to be an independent predictor of upgrading of low risk patient biopsies (odds ratio of 1.90) as one of the four criteria assessed in the validated BADGR nomogram (37).

\section{Other Clinical predictors}

Other less powerful clinical predictors for reclassification include low serum testosterone and race. Pichon et al. in a cohort taken to radical prostatectomy found GSU from predominant Gleason score 3 to predominant Gleason 4 more commonly in hypogonadal patients (total testosterone $<3$ ) when compared to patients with normal testosterone (20.1\% vs $11.6 \% \mathrm{P}=0.002)$ (47). In a more recent trial measured serum testosterone in 167 low risk PC patients eligible for AS that underwent RP revealed preoperative testosterone was lower in the upgraded compared to the non-upgraded group (3.72 vs 4.56, $\mathrm{P}<0.01$ ) (48).

African American (AA) men have a higher incidence of PC compared to other racial groups, and present with more advanced stages at diagnosis, more aggressive tumors and poorer outcomes (49). It is still uncertain if race is a prognostic factor for upgrading in AS cohorts. African American men with very low risk PC who met the criteria for AS but undergo RP experience significantly higher rates of upgrading and adverse pathology compared to other races (27.3 vs $14.4 \mathrm{P}<0.001$ ) (50) suggesting concern for AS in this cohort. However, major AS cohorts underrepresent minorities, only $6 \%$ to $10 \%$ of those men are African American, thus the oncologic outcomes of this particular subgroup of patients is unknown. In an effort to examine results from AS cohorts, Iremashvili et al. (38) analyzed a cohort of $24 \mathrm{AA}$ in AS and found an adjusted hazard ratio of 3.8 for reclassification on serial biopsy. In a large multiethnic cohort with 39 African American men on AS (Duke Prostate Centre), black race remained the sole predictor of treatment (HR 3.08, $P=0.01$ ) (51). Sundi et al. (52) also reported a significant higher rate of upgrading of AA compared to Caucasian men (32.7\% vs $12.6 \% \mathrm{p}<0.001)$. Further study with larger populations, and subtyping of different AA ethnicities is required before a definitive conclusion can be reached regarding this issue.

Having a first-degree family member with PC increases the risk of PC diagnosis (53). Family history is a well-known risk factor for PC, but literature is scarce and contradictory on whether it is a factor that predicts reclassification and AS failure. Some authors suggest that men with family history of PC have more aggressive tumors compared to patients with sporadic neoplasias (54), but more recent studies have found no difference in tumor features and reclassification among patients with or without PC background in their families $(55,56)$.

Cancer susceptibility genes (BRCA1-BRCA2) represent a special subgroup in whom there is a clear trend toward more aggressive tumors. These mutations are suspected in patients with strong family history of early breast, prostate and ovarian cancer. Carriers of this mutation are at higher risk to develop more aggressive disease and higher risk of developing metastatic disease. Recent work suggests that this subgroup of patients should not be considered for AS $(57,58)$.

Iremashvili et al. (59) analyzed the usefulness of PSA kinetics for surveillance of patients on AS. They followed up 314 patients on AS and analyzed PSA and its derivatives namely PSA density, PSA velocity, PSA doubling time and correlated them with the risk of progression on surveillance biopsies, first through fourth. They found that PSA velocity and PSA density were associated with the risk of progression only during the fourth biopsy and hence need a minimum follow-up of 4 years to be an efficient prediction 
tool. Kates et al. (60) have observed that using the PC Research International Active Surveillance (PRIAS) protocol, which uses PSA kinetics along with scheduled biopsies at 1,4 and 7 years compared to the John Hopkins Hospital (JHH) protocol of doing an annual biopsy alone in their AS cohort of 1125 men would increase the chance of an intervention by $12 \%$, thus questioning the validity of PSA kinetics in this setting. Therefore, PSA velocity appears less useful in the short term for predicting risk of failure.

\section{NOMOGRAMS}

Multiple prognostic models have been developed to calculate the probability of pathologic features in the prostatectomy specimen such as low grade, low volume or organ-confined disease $(35,37,61-63)$, but many nomograms have demonstrated low predictive accuracy and poor calibration upon external validation (Table-3). The utility of the nomograms to predict insignificant disease has been assessed in several studies. Iremashvili et al. evaluated and compared the ability of 4 nomograms (Capitanio et al., Chun et al., Kulkarni et al. and Moussa et al.) to predict GSU and found that all the nomograms were poorly calibrated and not ready for clinical application (63). Wong et al. revisited other four prognostic models and reported only a moderate range of predictive ability for the Kattan et al. model (64).

More recently, the performance of different radical prostatectomy-based prognostic tools in predicting biopsy progression were analyzed (Partin et al., Dinh et al., Kattan et al., Truong et al. and Kulkarni et al.) in AS patients and results indicate that the Kattan and Truong (BADGR) nomograms had a higher predictive value than the other tools and were able also to stratify patients into subgroups with different risk of progression at the time of diagnosis (65). These two nomograms have important differences, which

Table 3 - nomograms that predict pathologic (Gleason $>6$ ) upgrading at the time of radical prostatectomy and validation in as cohort.

\begin{tabular}{|c|c|c|c|c|c|}
\hline $\begin{array}{l}\text { Nomogram } \\
\text { (author) }\end{array}$ & $\begin{array}{l}\text { Patients } \\
\text { (no) }\end{array}$ & Primary outcome & Variables used for formulation of nomogram & $\begin{array}{l}\text { Predictive } \\
\text { accuracy } \\
\operatorname{rrp}(\mathrm{auc})\end{array}$ & $\begin{array}{l}\text { Accuracy in } \\
\left.\text { as * }^{*} \text { c-index }\right)\end{array}$ \\
\hline $\begin{array}{l}\text { BADGR } \\
\text { (Truong) }\end{array}$ & 413 & $\begin{array}{l}\text { Probability of Gleason } \\
\text { upgrading }\end{array}$ & $\begin{array}{c}\text { PSAD, BMI, \# Positive cores, Max \% cancer } \\
\text { core involvement }\end{array}$ & 0.753 & 0.671 \\
\hline Kulkarni & 175 & $\begin{array}{l}\text { Probability of Gleason } \\
\text { upgrading }\end{array}$ & $\begin{array}{c}\text { PSA, Age, Pathologist, DRE, PIN, TRUS } \\
\text { volume, Hypoechoic lesions on TRUS, Type } \\
\text { of biopsy, \% Cancer in biopsy }\end{array}$ & 0.71 & 0.609 \\
\hline Dinh & 5,581 & $\begin{array}{c}\text { Probability of Gleason } \\
\text { upgrading }\end{array}$ & Age, PSA, \% positive cores & NA & 0.560 \\
\hline Kattan & 409 & $\begin{array}{l}\text { Probability of indolent } \\
\text { tumors }\end{array}$ & $\begin{array}{l}\text { PSA, Clinical Stage, Primary Gleason, } \\
\text { Secondary Gleason, TRUS volume, Length of } \\
\text { cancer \& benign tissue in the biopsy material }\end{array}$ & 0.79 & 0.687 \\
\hline Partin & 5,629 & $\begin{array}{c}\text { Probability of } \\
\text { pathologically non } \\
\text { organ confined disease }\end{array}$ & PSA, Clinical stage, Gleason score & 0.702 & 0.537 \\
\hline
\end{tabular}

PSA = Prostate specific antigen; $\mathbf{P C}=$ Prostate Cancer; $\mathbf{T R U S}=$ transrectal ultrasound; $\mathbf{P S A D}=$ Prostate specific antigen density; $\mathbf{B M I}=$ Body mass index; $\mathbf{D R E}=$ Digital rectal examination; PIN = Prostate intraepithelial neoplasia

* Harrel's C- Index based on "Predictive models and risk of biopsy progression in active surveillance patients" by Iremashvili et al. (63) 
suggest that a more effective predicting model combining the strong sides of both tools could be developed (Table-3).

Truong et al. assessed more than 30 clinicopathological parameters and using multivariable logistic regression found PSAD, obesity, number of positive cores and maximum core involvement (BADGR nomogram) to be useful for predicting upgrading (Gleason $\geq 7$ ) on final pathology. An online risk calculator has been provided $\leq \mathrm{https}$ :// www.urology.wisc.edu/research/researcherslabs/ jarrard/prostate_cancer_predictor> (66). The BADGR and Kattan nomograms are very similar, the main difference between them is the inclusion of BMI and PSAD in the former. Notably, the BADGR nomogram is designed to predict pathological upgrading only for men diagnosed with Gleason 6 PC. The main outcome Kattan's tool is to determine the probability of pathologically indolent cancer in somewhat higher risk PC, thus the optimization of these two nomograms have a different focus.

\section{EVOLVING TECHNOLOGY FOR AS PATIENTS}

The focus of this review was on clinical and pathological parameters for predicting progression of grade on AS. However, newer approaches may help in stratifying patients that have factors that place them outside the very low risk group including MRI and genomic testing. Multiparametric MRI (MPMRI) has been shown to reduce misclassification rates due to biopsy and has been included in the current clinical guidelines in the United Kingdom (67). Although MRI lacks sensitivity for detecting low Gleason score cancer $(3+3)$, this might be deemed an advantage for choosing imaging negative patients for AS (68-70). However, MRI generates significant cost as well as missing roughly one-third of significant PCs (71). Incorporation of MPMRI into contemporary AS protocols will need large prospective trials to assess its impact on AS and the frequency of subsequent biopsies (72). MRI fusion is another technology that needs wider validation, but some studies have suggested it may enhance the detection of clinically relevant prostate cancers $(73,74)$.

Genome-based tests for detecting higher risk cancers have been a novel addition to the existing armamentarium of tools for stratifying AS patients. More widely validated tests include the Oncotype DX and Prolaris tests that utilize biopsy tissue. Oncotype DX is a 17-gene assay performed on biopsy tissue that has been shown to increase the percentage of patients choosing AS (75). Prolaris bases outcomes on the gene expression profile of 31 cell cycle progression (CCP) and 15 housekeeping genes in tissues obtained at the time of biopsy to predict aggressiveness of PC (76). Newer tests include Promark, a quantitative multiplex proteomics assay based on the expression pattern of eight protein markers to predict aggressive cancer (77). The downside of genomic testing is its significant cost (\$3800 USD) potentially limiting widespread usage. In addition, estimates have suggested that the majority of risk, roughly $70 \%$, can be determined by existing clinicopathologic parameters (78).

Finally, newer non-invasive testing may serve as an adjunct for monitoring patients on AS, including the PCA3 test. This urine-based test was analyzed in a longitudinal AS population of 240 men, but did not change longitudinally with grade reclassification (79). In another study, an incremental benefit was seen with PCA3 in an AS population for predicting Gleason $>6(80)$.

\section{CONCLUSIONS}

In order to determine the probability of a patient for disease progression during conservative treatment, it is not enough to extrapolate the information from radical prostatectomy cohorts, but will be imperative to get the data from actual AS patients that progress during follow up. In order to have more accurate data, we would have to wait for the current larger cohorts to mature more, because of prostate cancer's long natural history.

Currently, the data widely supports the use of very low risk PC features for selection of patients for AS (Gleason T1c, PSA $\leq 10$, Gleason $\leq 6, \leq 2$ positive biopsy cores, $\leq 50 \%$ cancer in any core, PSAD $<0.15$ ). Nomograms can be further used to stratify patients into higher risk groups for Gleason Score upgrading and subsequent reclassification during AS. Additional factors such as increased cancer volume, higher PSAD, increased body mass index, 
African American race or a genetic predisposition play a role in defining this increased risk. Higher risk subgroups may need a closer surveillance with more frequent biopsies (yearly), the inclusion of saturation biopsy approaches, compared to very low risk patients in which less strict protocols may be applied. The wider use of AS will ultimately benefit patients and criteria will continue to evolve as further information from longer-term AS cohorts matures and technology advances.

\section{ABBREVIATIONS}

\author{
$\mathrm{PC}=$ Prostate Cancer \\ $\mathrm{AS}=$ Active Surveillance \\ GSU=Gleason Score Upgrade \\ $\mathrm{RP}=$ Radical Prostatectomy \\ PSA=Prostate Specific Antigen \\ PSAD=Prostate Specific Antigen Density \\ $\mathrm{AA}=$ African American
}

\section{CONFLICT OF INTEREST}

None declared.

\section{REFERENCES}

1. Siegel RL, Miller KD, Jemal A. Cancer statistics, 2015. CA Cancer J Clin. 2015;65:5-29.

2. Roobol MJ, Kranse R, Bangma $\mathrm{CH}$, van Leenders $\mathrm{AG}$, Blijenberg BG, van Schaik RH, et al. Screening for prostate cancer: results of the Rotterdam section of the European randomized study of screening for prostate cancer. Eur Urol. 2013:64:530-9.

3. Hayes JH, Ollendorf DA, Pearson SD, Barry MJ, Kantoff PW, Lee PA, et al. Observation versus initial treatment for men with localized, low-risk prostate cancer: a cost-effectiveness analysis. Ann Intern Med. 2013;158:853-60.

4. Bangma $\mathrm{CH}$, Valdagni R, Carroll PR, van Poppel H, Klotz L, Hugosson J. Active surveillance for low-risk prostate cancer: developments to date. Eur Urol. 2015;67:646-8.

5. Godtman RA, Holmberg E, Khatami A, Stranne J, Hugosson J. Outcome following active surveillance of men with screen-detected prostate cancer. Results from the Göteborg randomised population-based prostate cancer screening trial. Eur Urol. 2013;63:101-7.

6. Cooperberg MR, Carroll PR. Trends in Management for Patients With Localized Prostate Cancer, 1990-2013. JAMA. 2015;314:80-2.
7. D'Amico AV, Whittington R, Malkowicz SB, Schultz D, Schnall $\mathrm{M}$, Tomaszewski JE, et al. A multivariate analysis of clinical and pathological factors that predict for prostate specific antigen failure after radical prostatectomy for prostate cancer. J Urol. 1995;154:131-8.

8. Bul M, Zhu X, Valdagni R, Pickles T, Kakehi Y, Rannikko $A$, et al. Active surveillance for low-risk prostate cancer worldwide: the PRIAS study. Eur Urol. 2013;63:597-603.

9. Carter HB. Active surveillance for prostate cancer: an underutilized opportunity for reducing harm. J Natl Cancer Inst Monogr. 2012;2012:175-83.

10. Klotz L, Vesprini D, Sethukavalan P, Jethava V, Zhang L, Jain $S$, et al. Long-term follow-up of a large active surveillance cohort of patients with prostate cancer. J Clin Oncol. 2015;33:272-7.

11. Tosoian JJ, Trock BJ, Landis P, Feng Z, Epstein JI, Partin AW, et al. Active surveillance program for prostate cancer: an update of the Johns Hopkins experience. J Clin Oncol. 2011;29:2185-90.

12. Chun FK, Steuber T, Erbersdobler A, Currlin E, Walz J, Schlomm $T$, et al. Development and internal validation of a nomogram predicting the probability of prostate câncer Gleason sum upgrading between biopsy and radical prostatectomy pathology. Eur Urol. 2006;49:820-6.

13. Pinthus JH, Witkos M, Fleshner NE, Sweet J, Evans A, Jewett MA, et al. Prostate cancers scored as Gleason 6 on prostate biopsy are frequently Gleason 7 tumors at radical prostatectomy: implication on outcome. J Urol. 2006;176:979-84.

14. Epstein JI, Feng Z, Trock BJ, Pierorazio PM. Upgrading and downgrading of prostate cancer from biopsy to radical prostatectomy: incidence and predictive factors using the modified Gleason grading system and factoring in tertiary grades. Eur Urol. 2012;61:1019-24.

15. Eggener SE, Scardino PT, Walsh PC, Han M, Partin AW, Trock BJ, et al. Predicting 15-year prostate cancer specific mortality after radical prostatectomy. J Urol. 2011;185:86975.

16. Yamamoto $T$, Musunuru B, Vesprini D, Zhang L, Ghanem G, Loblaw A, et al. Metastatic Prostate Cancer in Men Initially Treated with Active Surveillance. J Urol. 2016;195:1409-14.

17. Van Hemelrijck M, Garmo H, Lindhagen L, Bratt 0 , Stattin P, Adolfsson J. Quantifying the Transition from Active Surveillance to Watchful Waiting Among Men with Very Low-risk Prostate Cancer. Eur Urol. 2017;72:534-41.

18. Coen JJ, Feldman AS, Smith MR, Zietman AL. Watchful waiting for localized prostate cancer in the PSA era: what have been the triggers for intervention? BJU Int 2011;107:1582-6.

19. National Comprehensive Cancer Network. Prostate cancer 2017 [Available at. <https://www.nccn.org/professionals/ physician_gls/pdf/prostate.pdf $>$. 
20. Thompson I, Thrasher JB, Aus G, Burnett AL, CanbyHagino ED, Cookson MS, et al. AUA Prostate Cancer Clinical Guideline Update Panel. Guideline for the management of clinically localized prostate cancer: 2007 update. J Urol. 2007;177:2106-31.

21. Mottet N, Bellmunt J, Bolla M, Briers E, Cumberbatch MG, De Santis M, et al. EAU-ESTRO-SIOG Guidelines on Prostate Cancer. Part 1: Screening, Diagnosis, and Local Treatment with Curative Intent. Eur Urol.2017;71:618-629.

22. Chen RC, Rumble RB, Loblaw DA, Finelli A, Ehdaie $B$, Cooperberg MR, et al. Active Surveillance for the Management of Localized Prostate Cancer (Cancer Care Ontario Guideline): American Society of Clinical Oncology Clinical Practice Guideline Endorsement. J Clin Oncol. 2016;34:2182-90.

23. Overholser S, Nielsen M, Torkko K, Cwilka D, Weaver B, Shi $\mathrm{X}$, et al. Active Surveillance is an Appropriate Management Strategy for a Proportion of Men Diagnosed with Prostate Cancer by Prostate Specific Antigen Testing. J Urol. 2015;194:680-4.

24. Dall'Era M, Carroll P. What is the Optimal Way to Select Candidates for Active Surveillance of Prostate Cancer? J Urol. 2015;194:615-6.

25. Archive TCI. TCGA Prostate Phenotype Research Group. [Available at. <https://wiki.cancerimagingarchive.net/display/ Public/TCGA+Prostate+Phenotype+Research+Group >.

26. Epstein JI, Zelefsky MJ, Sjoberg DD, Nelson JB, Egevad L, Magi-Galluzzi C, et al. A Contemporary Prostate Cancer Grading System: A Validated Alternative to the Gleason Score. Eur Urol. 2016;69:428-35.

27. Bellardita $L$, Valdagni $R$, van den Bergh $R$, Randsdorp $H$, Repetto C, Venderbos LD, et al. How does active surveillance for prostate cancer affect quality of life? A systematic review. Eur Urol. 2015;67:637-45.

28. El Hajj A, Ploussard G, de la Taille A, Allory Y, Vordos $D$, Hoznek $A$, et al. Analysis of outcomes after radical prostatectomy in patients eligible for active surveillance (PRIAS). BJU Int. 2013;111:53-9.

29. Loeb S, Carter HB, Berndt SI, Ricker W, Schaeffer EM. Complications after prostate biopsy: data from SEERMedicare. J Urol. 2011;186:1830-4.

30. Hadway P, Barrett LK, Waghorn DJ, Hasan K, Bdesha A, Haldar $\mathrm{N}$, et al. Urosepsis and bacteraemia caused by antibioticresistant organisms after transrectal ultrasonographyguided prostate biopsy. BJU Int. 2009;104:1556-8.

31. Aly M, Dyrdak R, Nordström T, Jalal S, Weibull CE, Giske $\mathrm{CG}$, et al. Rapid increase in multidrug-resistant enteric bacilli blood stream infection after prostate biopsy - A 10-year population-based cohort study. Prostate. 2015;75:947-56.

32. Loeb S, Vellekoop A, Ahmed HU, Catto J, Emberton M, Nam $\mathrm{R}$, et al. Systematic review of complications of prostate biopsy. Eur Urol. 2013;64:876-92.
33. Porten SP, Whitson JM, Cowan JE, Cooperberg MR, Shinohara K, Perez N, et al. Changes in prostate cancer grade on serial biopsy in men undergoing active surveillance. $J$ Clin Oncol. 2011;29:2795-800.

34. Schiffmann J, Wenzel P, Salomon G, Budäus L, Schlomm T, Minner S, et al. Heterogeneity in D'Amico classificationbased low-risk prostate cancer: Differences in upgrading and upstaging according to active surveillance eligibility. Urol Oncol. 2015;33:329.e13-9.

35. Dinh KT, Mahal BA, Ziehr DR, Muralidhar V, Chen YW, Viswanathan VB, et al. Incidence and Predictors of Upgrading and Up Staging among 10,000 Contemporary Patients with Low Risk Prostate Cancer. J Urol. 2015;194:343-9.

36. Ibeawuchi C, Schmidt H, Voss R, Titze U, Abbas M, Neumann $J$, et al. Genome-wide investigation of multifocal and unifocal prostate cancer-are they genetically different? Int J Mol Sci. 2013;14:11816-29.

37. Truong M, Slezak JA, Lin CP, Iremashvili V, Sado M, Razmaria AA, et al. Development and multi-institutional validation of an upgrading risk tool for Gleason 6 prostate cancer. Cancer. 2013;119:3992-4002.

38. Iremashvili V, Soloway MS, Rosenberg DL, Manoharan M. Clinical and demographic characteristics associated with prostate cancer progression in patients on active surveillance. J Urol. 2012;187:1594-9.

39. Kotb AF, Tanguay S, Luz MA, Kassouf W, Aprikian AG. Relationship between initial PSA density with future PSA kinetics and repeat biopsies in men with prostate cancer on active surveillance. Prostate Cancer Prostatic Dis. 2011;14:53-7.

40. San Francisco IF, Werner L, Regan MM, Garnick MB, Bubley G, DeWolf WC. Risk stratification and validation of prostate specific antigen density as independente predictor of progression in men with low risk prostate cancer during active surveillance. J Urol. 2011;185:471-6.

41. Cary KC, Cowan JE, Sanford M, Shinohara K, Perez N, Chan JM, et al. Predictors of pathologic progression on biopsy among men on active surveillance for localized prostate cancer: the value of the pattern of surveillance biopsies. Eur Urol. 2014;66:337-42.

42. Margel D, Nandy I, Wilson TH, Castro R, Fleshner N. Predictors of pathological progression among men with localized prostate cancer undergoing active surveillance: a sub-analysis of the REDEEM study. J Urol. 2013;190:2039-45.

43. Freedland SJ, Isaacs WB, Platz EA, Terris MK, Aronson WJ, Amling CL, et al. Prostate size and risk of high-grade, advanced prostate cancer and biochemical progression after radical prostatectomy: a search database study. J Clin Oncol. 2005;23:7546-54

44. Davies JD, Aghazadeh MA, Phillips S, Salem S, Chang SS, Clark PE, et al. Prostate size as a predictor of Gleason score upgrading in patients with low risk prostate cancer. J Urol. 2011;186:2221-7. 
45. Gershman B, Dahl DM, Olumi AF, Young RH, McDougal WS, Wu CL. Smaller prostate gland size and older age predict Gleason score upgrading. Urol Oncol. 2013;31:1033-7.

46. de Cobelli O, Terracciano D, Tagliabue E, Raimondi S, Galasso $G$, Cioffi $A$, et al. Body mass index was associated with upstaging and upgrading in patients with low-risk prostate cancer who met the inclusion criteria for active surveillance. Urol Oncol. 2015;33:201.e1-8.

47. Pichon A, Neuzillet $\mathrm{Y}$, Botto H, Raynaud JP, Radulescu C, Molinié $\mathrm{V}$, et al. Preoperative low serum testosterone is associated with high-grade prostate cancer and an increased Gleason score upgrading. Prostate Cancer Prostatic Dis. 2015;18:382-7.

48. Gao Y, Jiang CY, Mao SK, Cui D, Hao KY, Zhao W, et al. Low serum testosterone predicts upgrading and upstaging of prostate câncer after radical prostatectomy. Asian J Androl. 2016;18:639-43.

49. Rebbeck TR, Devesa SS, Chang BL, Bunker CH, Cheng I, Cooney K, et al. Global patterns of prostate câncer incidence, aggressiveness, and mortality in men of african descent. Prostate Cancer. 2013;2013:560857.

50. Sundi D, Ross AE, Humphreys EB, Han M, Partin AW, Carter $\mathrm{HB}$, et al. African American men with very low-risk prostate cancer exhibit adverse oncologic outcomes after radical prostatectomy: should active surveillance still be na option for them? J Clin Oncol. 2013;31:2991-7.

51. Abern MR, Bassett MR, Tsivian M, Bañez LL, Polascik TJ, Ferrandino MN, et al. Race is associated with discontinuation of active surveillance of low-risk prostate cancer: results from the Duke Prostate Center. Prostate Cancer Prostatic Dis. 2013;16:85-90.

52. Sundi D, Faisal FA, Trock BJ, Landis PK, Feng Z, Ross AE, et al. Reclassification rates are higher among African American men than Caucasians on active surveillance. Urology. 2015;85:155-60.

53. Hemminki K. Familial risk and familial survival in prostate cancer. World J Urol. 2012;30:143-8.

54. Kupelian PA, Reddy CA, Reuther AM, Mahadevan A, Ciezki JP, Klein EA. Aggressiveness of familial prostate cancer. J Clin Oncol. 2006;24:3445-50.

55. Kundu S, HArshad F, Loeb S, Roehl KA, Mondo DM, Gashti $\mathrm{SN}$, et al. Should a family history of prostate cancer affect the total PSA or PSA velocity threshold for biopsy? J Urology. 2008; 179:714-5.

56. Selkirk CG, Wang CH, Lapin B, Helfand BT. Family history of prostate cancer in men being followed by active surveillance does not increase risk of being diagnosed with high-grade disease. Urology. 2015;85:742-7.

57. Castro E, Goh C, Leongamornlert D, Saunders E, Tymrakiewicz M, Dadaev T, et al. Effect of BRCA Mutations on Metastatic Relapse and Cause-specific Survival After Radical Treatment for Localised Prostate Cancer. Eur Urol. 2015;68:186-93.
58. Bratt O, Loman N. Clinical Management of Prostate Cancer in Men with BRCA Mutations. Eur Urol. 2015;68:194-5.

59. Iremashvili V, Kava BR, Manoharan M, Parekh DJ, Punnen S. Is It Time to Revisit the Role of Prostate-specific Antigen Kinetics in Active Surveillance for Prostate Cancer? Urology. 2016;95:139-44.

60. Kates M, Tosoian JJ, Trock BJ, Feng Z, Carter HB, Partin AW. Indications for intervention during active surveillance of prostate cancer: a comparison of the Johns Hopkins and Prostate Cancer Research International Active Surveillance (PRIAS) protocols. BJU Int. 2015;115:216-22.

61. Kattan MW, Eastham JA, Stapleton AM, Wheeler TM, Scardino PT. A preoperative nomogram for disease recurrence following radical prostatectomy for prostate cancer. J Natl Cancer Inst. 1998;90:766-71.

62. Kulkarni GS, Lockwood G, Evans A, Toi A, Trachtenberg J, Jewett MA, et al. Clinical predictors of Gleason score upgrading: implications for patients considering watchful waiting, active surveillance, or brachytherapy. Cancer. 2007;109:2432-8.

63. Partin AW, Kattan MW, Subong EN, Walsh PC, Wojno KJ, Oesterling JE, et al. Combination of prostate-specific antigen, clinical stage, and Gleason score to predict pathological stage of localized prostate cancer. A multi-institutional update. JAMA. 1997;277:1445-51.

64. Capitanio U, Karakiewicz PI, Valiquette L, Perrotte P, Jeldres C, Briganti A, et al. Biopsy core number represents one of foremost predictors of clinically significant gleason sum upgrading in patients with low-risk prostate cancer. Urology. 2009;73:108791.

65. Moussa AS, Jones JS, Yu C, Fareed K, Kattan MW. Development and validation of a nomogram for predicting a positive repeat prostate biopsy in patients with a previous negative biopsy session in the era of extended prostate sampling. BJU international. 2010;106:1309-14.

66. Dr. Jarrard's Lab. University of Wisconsin Biopsy-integrated Algorithm for Determining Gleason 6 Upgrading Risk (BADGR). [Available at. <https://www.urology.wisc.edu/research/ researchers-labs/jarrard/prostate_cancer_predictor $>$.

67. Excellence NlfHaC. Prostate cancer: diagnosis and management. [Available at. <https://www.nice.org.uk/guidance/cg175>.

68. Lee DH, Koo KC, Lee SH, Rha KH, Choi YD, Hong SJ, et al. Low-risk prostate cancer patients without visible tumor (T1C) on multiparametric MRI could qualify for active surveillance candidate even if they did not meet inclusion criteria of active surveillance protocol. Jpn J Clin Oncol. 2013;43:553-8.

69. Barentsz J0, Richenberg J, Clements R, Choyke P, Verma S, Villeirs G, et al. ESUR prostate MR guidelines 2012. Eur Radiol. 2012;22:746-57.

70. Dianat SS, Carter HB, Pienta KJ, Schaeffer EM, Landis PK, Epstein $\mathrm{JI}$, et al. Magnetic resonance-invisible versus magnetic resonancevisible prostate cancer in active surveillance: a preliminary report on disease outcomes. Urology. 2015;85:147-53. 
71. Le JD, Tan N, Shkolyar E, Lu DY, Kwan L, Marks LS, et al. Multifocality and prostate cancer detection by multiparametric magnetic resonance imaging: correlation with whole-mount histopathology. Eur Urol. 2015;67:569-76.

72. Passoni NM, Polascik TJ. Targeted prostate biopsies: the complexity behind a simple concept. Eur Urol. 2014;66:30-1.

73. Sonn GA, Natarajan S, Margolis DJ, MacAiran M, Lieu P, Huang J, et al. Targeted biopsy in the detection of prostate cancer using an office based magnetic resonance ultrasound fusion device. J Urol. 2013;189:86-91.

74. Haffner J, Lemaitre L, Puech P, Haber GP, Leroy X, Jones $\mathrm{JS}$, et al. Role of magnetic resonance imaging before initial biopsy: comparison of magnetic resonance imagingtargeted and systematic biopsy for significant prostate cancer detection. BJU Int. 2011;108(8 Pt 2):E171-8.

75. Albala D, Kemeter MJ, Febbo PG, Lu R, John V, Stoy D, et al. Health Economic Impact and Prospective Clinical Utility of Oncotype DX® Genomic Prostate Score. Rev Urol. 2016;18:123-32.

76. Cooperberg MR, Simko JP, Cowan JE, Reid JE, Djalilvand A, Bhatnagar $S$, et al. Validation of a cell-cycle progression gene panel to improve risk stratification in a contemporary prostatectomy cohort. J Clin Oncol. 2013;31:1428-34.

77. Blume-Jensen P, Berman DM, Rimm DL, Shipitsin M, Putzi $M$, Nifong TP, et al. Development and clinical validation of an in situ biopsy-based multimarker assay for risk stratification in prostate cancer. Clin Cancer Res. 2015;21:2591-600.
78. Leyh-Bannurah SR, Abou-Haidar H, Dell'Oglio P, Schiffmann $\mathrm{J}$, Tian Z, Heinzer $\mathrm{H}$, et al. Primary Gleason pattern upgrading in contemporary patients with D'Amico low-risk prostate cancer: implications for future biomarkers and imaging modalities. BJU Int. 2017;119:692-9.

79. Tosoian JJ, Patel HD, Mamawala M, Landis P, Wolf S, Elliott DJ, et al. Longitudinal assessment of urinary PCA3 for predicting prostate cancer grade reclassification in favorable-risk men during active surveillance. Prostate Cancer Prostatic Dis. 2017;20:339-42.

80. Lin DW, Newcomb LF, Brown EC, Brooks JD, Carroll PR, Feng $Z$, et al. Urinary TMPRSS2:ERG and PCA3 in an active surveillance cohort: results from a baseline analysis in the Canary Prostate Active Surveillance Study. Clin Cancer Res. 2013;19:2442-50.

Correspondence address: David Jarrard, MD Department of Urology University of Wisconsin School of Medicine and Public Health 1111 Highland Avenue, Madison, WI 53792 Telephone: + 1608 252-0937 E-mail: jarrard@urology.wisc.edu 